Hemipelvic resections for primary bone tumours require reconstruction to restore weight bearing along anatomic axes. However, reconstruction of the pelvic arch remains a major surgical challenge because of the high rate of associated complications. We used the pedicle screw-rod system to reconstruct the pelvis, and the purpose of this investigation was to assess the oncology, functional outcome and complication rate following this procedure. The purpose of this study was to investigate the operative indications and technique of the pedicle screw-rod system in reconstruction of the stability of the sacroiliac joint after resection of sacroiliac joint tumours. The average MSTS (Musculoskeletal Tumour Society) score was 26.5 at either three months after surgery or at the latest follow-up. Seven patients had surgery-related complications, including wound dehiscence in one, infection in two, local necrosis in four (including infection in two), sciatic nerve palsy in one and pubic symphysis subluxation in one. There was no screw loosening or deep vein thrombosis occurring in this series. Using a pedicle screw-rod after resection of a sacroiliac joint tumour is an acceptable method of pelvic reconstruction because of its reduced risk of complications and satisfactory functional outcome, as well as its feasibility of reconstruction for type IV pelvis tumour resection without elaborate preoperative customisation. Level of evidence: Level IV, therapeutic study.

Key words: sacroiliac joint, tumour, hemipelvectomy, reconstruction.

Contemp Oncol (Pozn) 2016; 20 (1): 73-79 DOI: $10.5114 /$ wo.2016.58503

\section{The pedicle screw-rod system is an acceptable method of reconstructive surgery after resection of sacroiliac joint tumours}

\author{
Yi-Jun Zhou*, Akbar Yunus, Zheng Tian, Jiang-Tao Chen*, Chong Wang, \\ Lei-Lei $\mathrm{Xu}$, Xing-Hua Song
}

Orthopaedic Department, The First Affiliated Hospital of Xinjiang Medical School, Urumqi, PR China

*The authors have contributed equally to this paper and are co-first authors for this article.

\section{Introduction}

Because the anatomy of the pelvis is complex, extensile exposure is a surgical challenge and there is a need to identify and preserve major neurovascular structures. Reconstructive surgery about the pelvis is complex, so restoring anatomy for the hip and retaining function for the muscles is not simple and requires more time and ingenuity than procedures in other anatomic sites. Involvement of the iliac and sacroiliac joint with tumours is not uncommon; treatment is difficult due to the anatomy of the pelvis. Resection of the tumour mass must be extensive in order to achieve safe margins, but this may lead to instability and poor results. Several reconstruction options have been proposed, including massive allograft, allograft prosthesis composite, custom-made endoprosthesis combined with hip arthroplasty, saddle prosthesis or a modular hemipelvic prosthesis, with its advantages and limitations [1-4]. However, these different methods have been fraught with a high complication rate; complications include loosening, dislocation, non union and infection, which can lead to failure of reconstruction and subsequent removal of the allograft or prosthesis. Partial resection of the pelvis or sacroiliac joint is an uncommon procedure, typically performed in the setting of tumours, severe infections or trauma. The resultant defects, depending on the size and location, may cause significant postoperative morbidity or functional impairment. It is therefore essential that the surgeon be aware of all reconstructive options available and implement the most appropriate option [5].

Mankin et al. reported the mean survival for patients with high-grade malignant pelvic tumours to be approximately 50\%; the type of surgical treatment appeared to make little difference in patient outcome, so appropriate reconstruction methods must warrant the lowest complication rate and rapid rehabilitation [6]. Johnson advocated reconstruction of a pelvic defect with a prosthesis and cement, and Satcher reported the reconstruction using Steinmann pins with bone cement filling in areas of bone loss, in combination with total hip arthroplasty, with excellent functional outcome and lower complication rate [7]. We modified these methods with the pedicle screw-rod system augmented with autologous bone graft, which is easy to use in surgery following a primary pelvic tumour resection (Fig. 1). Furthermore, this procedure could be used in defect reconstruction due to type IV sacroiliac joint tumour resection without preoperative customisation. The purpose of this study was to assess the functional outcome and complication rate following treatment with the USS pedicle screw-rod system to reconstruct the sacroiliac joint after resection of a sacroiliac joint tumour, 


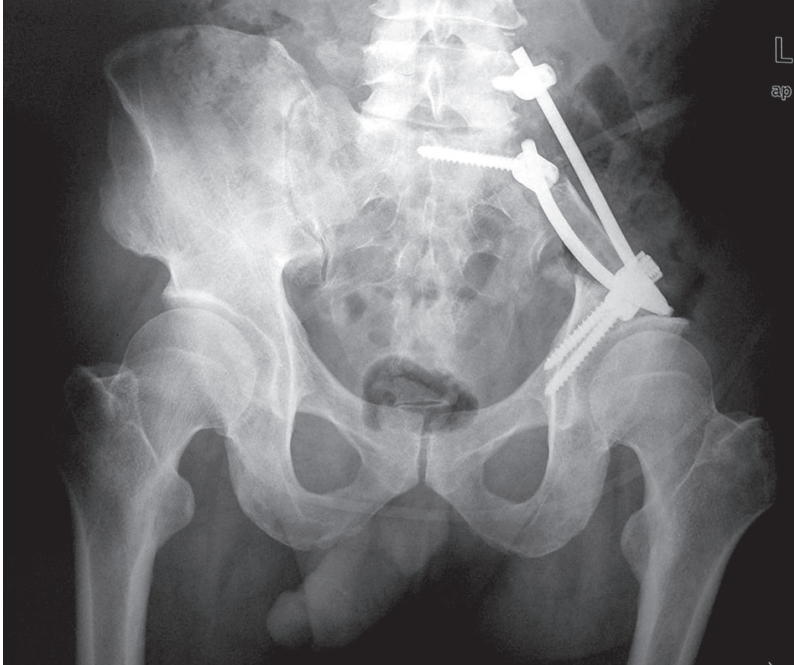

Fig. 1. Modified method with the pedicle screw-rod system augmented with autologous bone graft

and further to provide an effective and simple procedure of sacroiliac joint reconstruction.

\section{Material and methods}

We retrospectively reviewed 16 patients who had hemipelvic prosthesis reconstruction using the pedicle screwrod system after pelvic resection for primary sacroiliac joint tumours at the first affiliated hospital of Xinjiang Medical University between 2000 and 2012. Data from the current study were referred from hospital records, maintained oncological files and clinical examination at followup. These data included the type of surgical resection [8], the achieved surgical curative effect according to the of the MSTS system [9], any complications or need for reoperation, incidence of local recurrence and distant metastases, the current oncological status and the functional outcome.

Our database contained 6 (37.5\%) men and 10 (62.5\%) women. Their ages ranged from 12 to 73 years with a mean of 42 years. Follow up ranged from 3 months to 80 years (mean: 35 months).

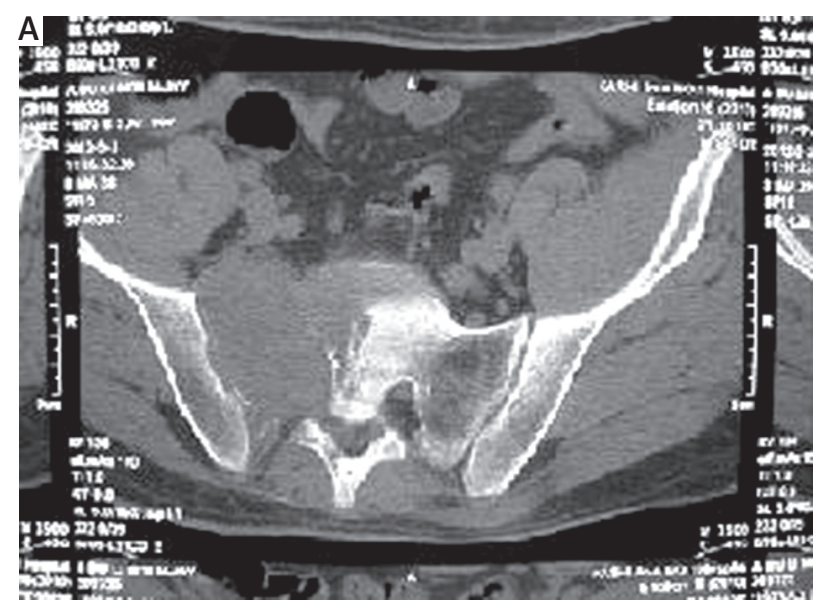

Fig. 2. Preoperative staging and assessment of tumor resectability - computed tomography scan

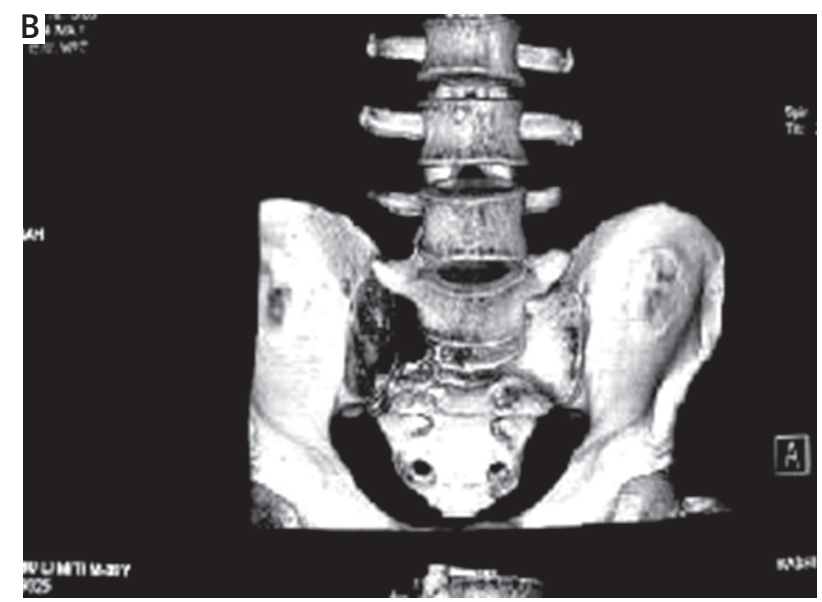

The diagnoses included chondrosarcoma in 4 patients (25\%), osteosarcoma in three patients (18.8\%), and giant cell tumour in three patients (18.8\%). We found one case of each of the following diagnoses: angiosarcoma, plasmacytoma, synovial sarcoma, malignant fibrous histiocytoma, adenocarcinoma and transitional cell carcinoma (surgical biopsy was preoperatively performed in all patients). Fourteen tumours were classified as stage-IIB lesions and two as stage-IIIA lesions according to the system of the Musculoskeletal Tumour Society. Three (18.8\%) patients had lung metastasis at presentation. One (6.3\%) patient had adenocarcinoma that was derived from liver metastatic progression and one (6.3\%) patient had transitional cell carcinoma that was derived from kidney metastatic progression.

Two patients (12.5\%) received radiotherapy. This included one patient (6.3\%) who had postoperative radiotherapy and one patient (16.7\%) who had preoperative and postoperative radiotherapy, included primary focal: 40-60 Gy per four to six weeks and lymph node metastases 40-50 Gy. Eight patients (50\%) received chemotherapy. This included five patients (32.2\%) who had postoperative radiotherapy, and three patients (18.8\%) who had preoperative and postoperative radiotherapy. Chemotherapy drugs included: adriamycin, cisplatin, methotrexate (MTX), cyclophosphamide, doxorubicin, actinomycin D, VP-16, cisplatin, DTIC, alanine nitrogen mustard and etoposide.

Preoperative staging and assessment of tumour resectability were accomplished with computed tomography scans (Fig. 2) and magnetic resonance imaging (Fig. 3) in all patients. The extraosseous component of the tumour was assessed for resectability and to address possible pelvic organ involvement. Twelve (75\%) had type IV (sacroiliac joint) pelvic resections, one (6.25\%) had types I + II + IV (ilium and periacetabular and sacroiliac joint) pelvic resections, two (12.5\%) patients had types IV + I (sacroiliac joint and ilium) pelvic resections and one (6.25\%) had types III + IV (pubis and sacroiliac joint) pelvic resections.

Functional outcome was determined using the MSTS system at three months after surgery or the latest followup. The MSTS system score measures patient activity, including pain, function, emotional acceptance, support, 

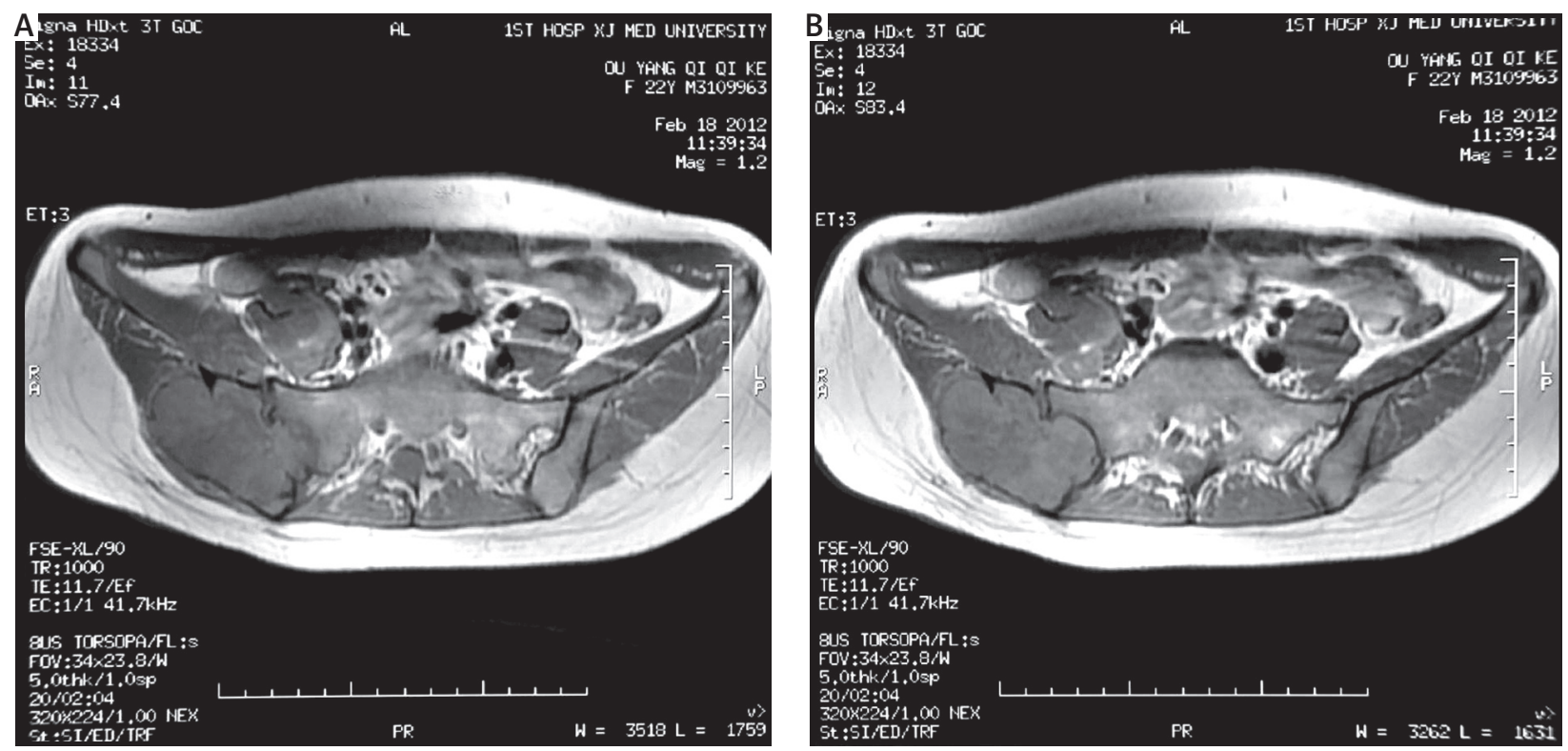

Fig. 3. Preoperative staging and assessment of tumor resectability - magnetic resonance imaging

walking ability and gait. Each of these six variables was assessed on a 5-point scale, giving a maximum score of 30 points, which we recorded as 100\% [9, 10]. The complications, including surgery-related complications and mechanical failures, were determined at the final followup. Abductor function was assessed by noting the absence or presence of the Trendelenburg sign on gait and stance, and by palpation during voluntary muscle contraction.

Statistical analysis was carried out using the SPSS software package for Windows. Means of all functional scores were calculated in order to measure the central tendency. Fisher's exact test was used to compare the surgical margins obtained and the incidence of local recurrence and metastases. $P$-values less than 0.05 were considered significant.

\section{Surgical technique}

Before the operation, the patients underwent complete bowel preparation. Preoperative antibiotics were administered. Surgery was performed under general anaesthesia with endotracheal intubation. Patients were placed in floating position to allow forward and backward movement of the patient during the procedure. The dissection was carried over the iliac crest subperiosteally to the major sciatic notch and to the sacroiliac joint posteriorly. The iliac wing was exposed medially to the major sciatic notch and the tumour was exposed. The tumour mass was removed en bloc including the sacroiliac joint and sacral ala.

The first step of the procedure was fixation. Two or three polyaxial pedicle screws with 6.5-7 $\mathrm{mm}$ diameter were inserted transversely into the sacrum and lumbar 5 . Two or three polyaxial pedicle screws, also $6.5 \mathrm{~mm}$ in diameter, were inserted into the remaining pubic and ischial bone, respectively, after making a pathway with a pedicle finder and checking it with a probe to make sure there was no breech or fracture. Sacral and pelvic screws were connected by two rods. In the next step, a strut bone graft was harvested from the ipsilateral fibula or the remaining ilium and was placed between the rods so that it would bridge the shortest distance between the sacrum and acetabular dome (Fig. 4). A split mesh was placed around the implants and was filled with $60 \mathrm{ml}$ of bone chip allograft in order to build up an artificial ilium-like bony mass. Four suction drains were placed into the surgical area. The procedure ended with closure of the wound.

Twelve of sixteen patients started to mobilise with crutches and partial weight-bearing for 4-8 weeks followed by full weight-bearing (not including four patients who died). They have remained pain free and ambulatory for more than 12 weeks at present. Radiological results were also satisfactory (Fig. 5).

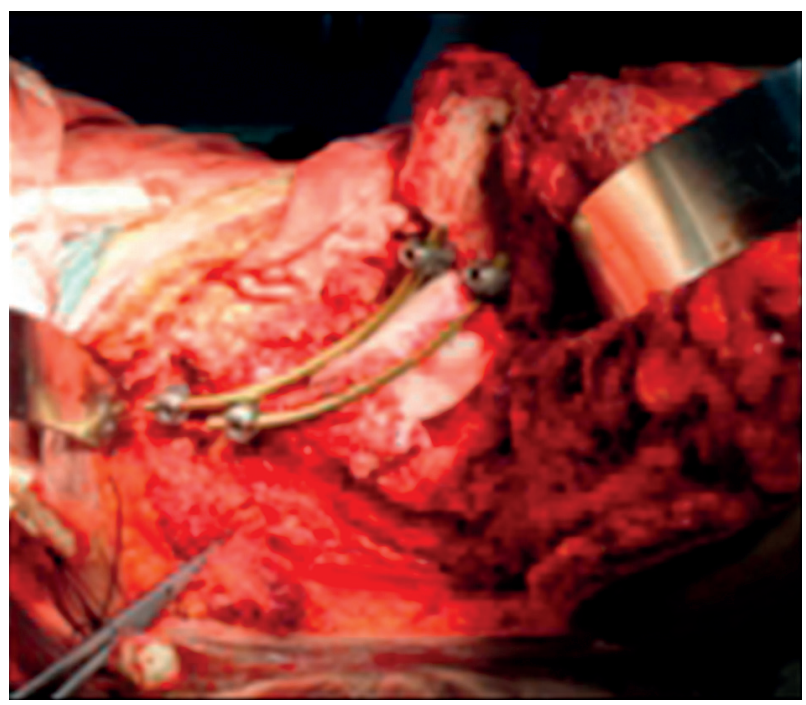

Fig. 4. A strut bone graft placed between the rods so that it would bridge the shortest distance between the sacrum and acetabular dome 

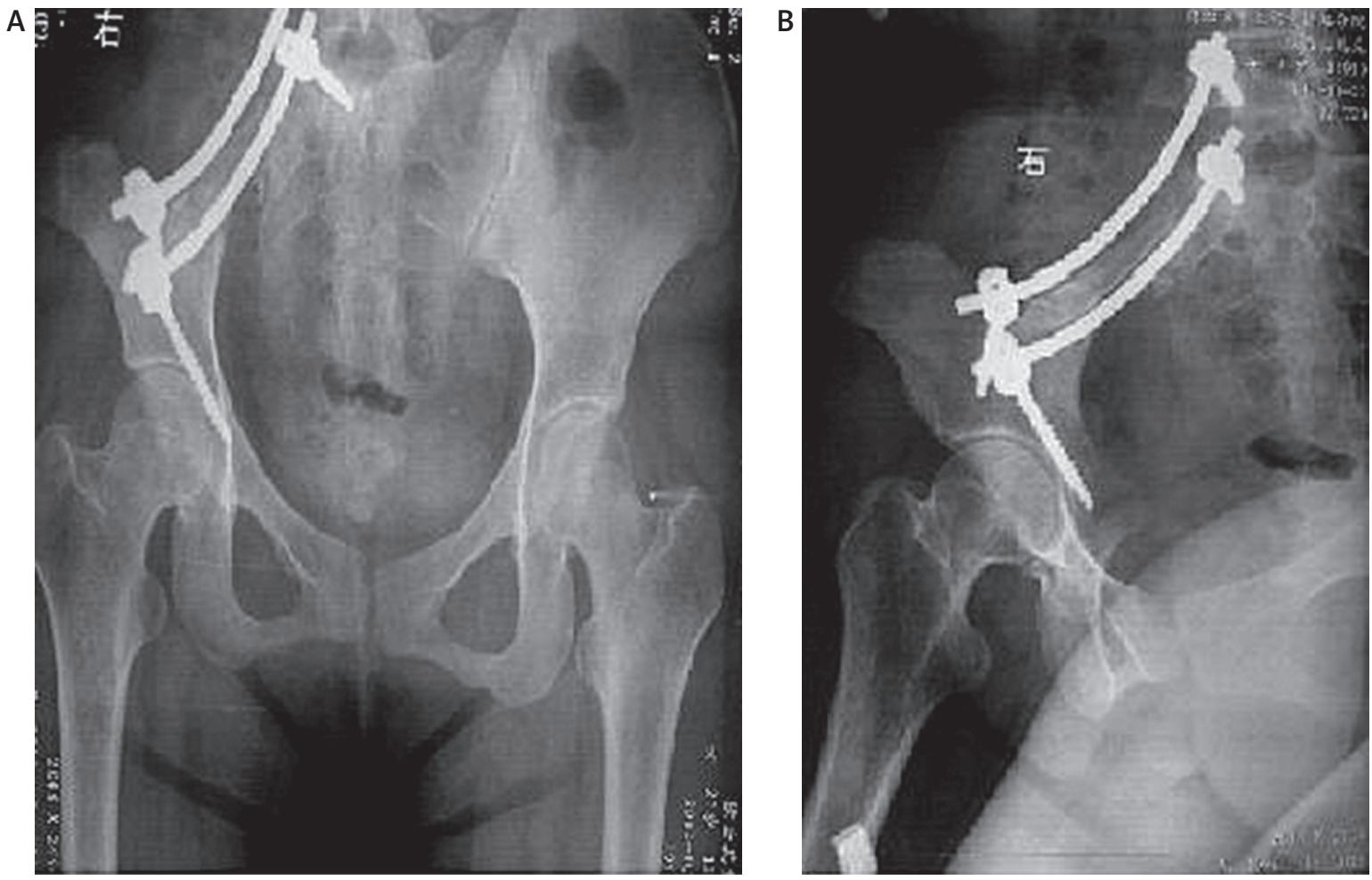

Fig. 5. Radiological results of use of the pedicle screw-rod system

\section{Results}

The mean operative blood loss was $1337.5 \mathrm{ml}$ (range: 700-2300 ml) and the mean operative time was $182.5 \mathrm{~min}$ utes (range: 100-290 minutes). No patient had any form of soft-tissue reconstruction. Resection margins were wide in eleven patients $(68.7 \%)$, marginal in four patients $(25 \%)$ and intralesional in one patient (6.3\%).

The average survival from the time of diagnosis was 35 months (range: 3-80 months). At latest followup, six patients $(37.5 \%)$ had no evidence of disease, four patients (25\%) died of their primary tumours and six patients (37.5\%) were continuously disease-free. Local recurrence occurred in four patients (25\%): two patients with a surgical procedure of marginal margin (50\%), and two patients with a surgical procedure of wide margin (18.1\%). There was no significant difference between the incidence of local recurrence and the achieved surgical margin ( $p>0.05)$. In four patients with local recurrence, one had additional resection, one died of his primary tumour and two were observed without treatment. Three of sixteen patients (18.8\%) showed lung metastatic progression. Two patients with osteosarcoma had metastases after local recurrence and died of disease 19 and 45 months after surgery, respectively. One patient with malignant fibrous histiocytoma had lung metastases and subsequent local relapse and died of disease 30 months after surgery. One of 16 patients (6.25\%) showed metastatic progression deriving from the liver (alive with disease 3 months after surgery), and one of 16 patients (6.25\%) showed metastatic progression deriving from the kidney (died of disease 30 months after surgery). There was no significant difference between the incidence of metastasis and the achieved surgical margin $(p>0.05)$. In addition, it was not possible to demonstrate a correlation between metastasis and the zones of tumour involvement.

The average MSTS score was 26.5 at three months after surgery or the latest followup. Pain was relieved in all patients after surgery. The average score for pain was 3.8 out of 5 points (76\%). The average rating of emotional acceptance was 3.9 out of 5 points (78\%), the average score for support was 4.9 out of 5 points (98\%), the average score for walking was 4.7 out of 5 points (94\%), the average score for gait was 4.4 out of 5 points (88\%), and the average score for function was 4.7 out of 5 points (94\%).

Eleven (68.8\%) patients had no complications perioperatively or during the followup period. Of the remaining five patients, four patients were treated non-operatively: one patient with sciatic nerve palsy who recovered completely after six months postoperatively; two patients with infection and one with skin necrosis, who recovered completely after being treated with antibiotics, regular dressing and physiotherapy (range: two to four weeks). One patient with complications had additional surgery: wound dehiscence treated with debridement and resection of a portion of the anterior iliac crest to decrease the skin tension, and healed uneventfully. Simultaneously, the patient had pubic symphysis subluxation seven mouths after surgery. There was no screw loosening or deep vein thrombosis occurring in this series (Tables 1 and 2).

\section{Discussion}

Approximately $10 \%$ to $15 \%$ of all primary malignant bone tumours involve the pelvis [11]. Most of the pelvic tumours are extracompartmental tumours. The extended re- 
Table 1. Patient diagnosis and oncology outcome

\begin{tabular}{|c|c|c|c|c|c|c|c|c|c|c|c|}
\hline Case & Age & Gender & $\begin{array}{l}\text { Follow- } \\
\text { up }\end{array}$ & Diagnosis & Staging & $\begin{array}{c}\text { Blood } \\
\text { loss }\end{array}$ & $\begin{array}{l}\text { Operation } \\
\text { time }\end{array}$ & Margin & $\begin{array}{l}\text { Local } \\
\text { recurrence }\end{array}$ & $\begin{array}{c}\text { Site of } \\
\text { metastasis }\end{array}$ & $\begin{array}{l}\text { Oncologic } \\
\text { results }\end{array}$ \\
\hline 1 & 41 & M & 3 & adenocarcinoma & III A & 2300 & 220 & W & $\mathrm{N}$ & liver & CDF \\
\hline 2 & 23 & $\mathrm{~F}$ & 7 & GCT & $\| \mathrm{B}$ & 1200 & 180 & W & $\mathrm{N}$ & $\mathrm{N}$ & CDF \\
\hline 3 & 75 & $\mathrm{~F}$ & 10 & sarcoma & II B & 1300 & 150 & M & $\mathrm{N}$ & N & CDF \\
\hline 4 & 39 & M & 12 & plasmacytoma & $\| \mathrm{B}$ & 1000 & 190 & W & $\mathrm{N}$ & $\mathrm{N}$ & CDF \\
\hline 5 & 59 & M & 16 & chondrosarcoma & II B & 1800 & 100 & W & Y & N & NED \\
\hline 6 & 43 & $\mathrm{~F}$ & 18 & chondrosarcoma & II B & 800 & 290 & W & Y & N & NED \\
\hline 7 & 20 & $\mathrm{~F}$ & 19 & sarcoma & $\| \mathrm{B}$ & 700 & 120 & W & $\mathrm{N}$ & lung & DOD \\
\hline 8 & 46 & M & 30 & $\begin{array}{l}\text { transitional cell } \\
\text { carcinoma }\end{array}$ & III A & 1800 & 200 & M & Y & kidney & DOD \\
\hline 9 & 73 & $\mathrm{~F}$ & 30 & $\mathrm{MFH}$ & II B & 1500 & 180 & $M$ & $\mathrm{~N}$ & lung & DOD \\
\hline 10 & 66 & $\mathrm{~F}$ & 36 & chondrosarcoma & $\| \mathrm{B}$ & 800 & 120 & W & $N$ & $\mathrm{~N}$ & CDF \\
\hline 11 & 17 & M & 45 & sarcoma & $\| \mathrm{B}$ & 1600 & 200 & W & $N$ & lung & DOD \\
\hline 12 & 40 & $\mathrm{~F}$ & 56 & $\mathrm{GCT}$ & II B & 1400 & 210 & W & $\mathrm{N}$ & $\mathrm{N}$ & NED \\
\hline 13 & 47 & $\mathrm{~F}$ & 56 & angiosarcoma & II B & 1900 & 205 & I & $\mathrm{N}$ & $\mathrm{N}$ & CDF \\
\hline 14 & 12 & $\mathrm{~F}$ & 67 & $\mathrm{GCT}$ & II B & 800 & 175 & W & $\mathrm{N}$ & N & NEN \\
\hline 15 & 36 & M & 75 & synovisarcoma & II B & 900 & 160 & M & Y & $\mathrm{N}$ & NED \\
\hline 16 & 33 & $\mathrm{~F}$ & 80 & chondrosarcoma & $\| \mathrm{B}$ & 1600 & 220 & W & $\mathrm{N}$ & $\mathrm{N}$ & NED \\
\hline
\end{tabular}

Table 2. Patient complications and functional outcome

\begin{tabular}{|c|c|c|c|c|c|c|c|c|c|c|c|}
\hline Case & $\begin{array}{l}\text { Radio- } \\
\text { therapy }\end{array}$ & $\begin{array}{l}\text { Chemo- } \\
\text { therapy }\end{array}$ & $\begin{array}{c}\text { Defect } \\
\left(\mathrm{cm}^{2}\right)\end{array}$ & $\begin{array}{l}\text { Additional } \\
\text { procedure }\end{array}$ & $\begin{array}{l}\text { Emotional } \\
\text { acceptance }\end{array}$ & Supports & $\begin{array}{l}\text { Walking } \\
\text { ability }\end{array}$ & Gait & Pain & Function & $\begin{array}{c}\text { Other } \\
\text { complications }\end{array}$ \\
\hline 1 & $\mathrm{~N}$ & Y & $30 * 20$ & $N$ & 5 & 5 & 5 & 4 & 3 & 5 & $\mathrm{~N}$ \\
\hline 2 & N & N & $10 * 10$ & debridement & 5 & 5 & 5 & 4 & 4 & 5 & fat liquefaction \\
\hline 3 & $N$ & $N$ & $13^{\star} 11$ & $N$ & 4 & 5 & 5 & 4 & 4 & 5 & $N$ \\
\hline 4 & Y & $\mathrm{N}$ & $9 * 8$ & $N$ & 4 & 5 & 5 & 4 & 4 & 5 & $N$ \\
\hline 5 & $N$ & Y & $17^{\star} 10$ & $N$ & 4 & 5 & 4 & 4 & 3 & 4 & $N$ \\
\hline 6 & $N$ & $N$ & $17^{\star} 12$ & $N$ & 4 & 5 & 4 & 4 & 4 & 4 & $N$ \\
\hline 7 & $N$ & $N$ & $15^{\star} 15$ & $N$ & 3 & 4 & 5 & 4 & 3 & 4 & $N$ \\
\hline 8 & $N$ & Y & $12^{\star} 13$ & $N$ & 4 & 5 & 5 & 5 & 2 & 5 & $N$ \\
\hline 9 & $N$ & Y & $8 * 7$ & $N$ & 3 & 5 & 4 & 5 & 3 & 4 & $N$ \\
\hline 10 & $N$ & Y & $13^{\star} 14$ & $N$ & 3 & 5 & 5 & 5 & 5 & 5 & $N$ \\
\hline 11 & Y & Y & $20 \star 18$ & $N$ & 3 & 5 & 4 & 5 & 3 & 4 & $\begin{array}{c}\text { sciatic nerve } \\
\text { palsy }\end{array}$ \\
\hline 12 & $N$ & $\mathrm{~N}$ & $11^{\star} 13$ & $N$ & 4 & 5 & 5 & 5 & 5 & 5 & $N$ \\
\hline 13 & $N$ & Y & $9 * 8$ & $N$ & 4 & 5 & 5 & 5 & 4 & 5 & $N$ \\
\hline 14 & $N$ & $N$ & $13^{\star} 11$ & $N$ & 4 & 5 & 5 & 5 & 4 & 5 & $N$ \\
\hline 15 & $N$ & $\mathrm{~N}$ & $18^{\star} 23$ & $\begin{array}{l}\text { lesion } \\
\text { resection }\end{array}$ & 4 & 5 & 5 & 4 & 5 & 5 & $N$ \\
\hline 16 & $N$ & Y & $12^{\star} 13$ & $N$ & 4 & 5 & 5 & 4 & 5 & 5 & $N$ \\
\hline
\end{tabular}

gional venous drainage pattern, especially in the sacroiliac and presacral regions, may play an additional role in the poor prognosis of pelvic malignancies, facilitating development of distant metastases [12].

The second area of concern is the ilium or sacrum as the site of the proximal margin of resection [13]. Although magnetic resonance imaging (MRI) provides an excellent approximation of the proximal extent of the disease, it is difficult to translate this information into a complex three-dimensional operative anatomy of the pelvis. To achieve wide resection margins in the bone, the use of a three-dimensional model of the pelvis has proven to be a useful tool. Regarding tumour extent in MRI the sites of osteotomy were marked on the model, which allowed better orientation during surgery, providing healthy wide margins in patients. However, the 3D model was more suitable 
for tumour resection and reconstruction in the bone. If the tumour invaded soft tissue, this method was inadequate [12]. For this reason, in our study all of the patients underwent MRI and CT (computed tomography) three-dimensional reconstruction.

Complication rates are reportedly as high as $60 \%$, with $40 \%$ of patients needing one or more repeat surgeries [14]. Complications may occur during the tumour excision, or they can be induced by an ill-designed prosthesis and poor reconstructive technique. An appropriately designed prosthesis can help reduce surgical risk and the duration of surgery and produce quite good functional recovery. For large tumours, it is difficult to have tumour-free margins, even with a hindquarter amputation, which could produce a relatively high recurrence rate. In this study, all of the patients used the USS pedicle screw-rod system to reconstruct the sacroiliac joint after resection of a tumour. Because the pedicle screw-rod system has a simple design, an uncomplicated procedure and can obviously shorten the operation time, we use it to reconstruct sacroiliac joints and to reduce the incidence of complications.

Most of these complications consist of local infections or wound-healing problems, such as skin necrosis or sinus haematoma $[14,15]$. In our study, wound-healing difficulties arose in one patient, one had skin margin necrosis of the incision and two had necrosis of the subcutaneous tissue (i.e. the two patients with infections). All of the these patients had blood transfusions greater than $1600 \mathrm{ml}$. Such large transfusions increase the risk of wound-healing problems, and they may account for the rapid local recurrence and metastasis [16].

Infection remains a frequent complication of reconstruction with hemipelvic allografts or autoclaved grafts and prosthesis after internal hemipelvectomy, with reported rates varying from $12 \%$ to $47 \%[1,7,17,18]$. These infections may be attributed to the immunosuppression caused by preoperative chemotherapy, as reported by some authors. The following factors contribute to the high risk of infection: the prolonged surgical time necessary to resect pelvic tumours, the proximity of the rectum and genitourinary tract, the large dead space after pelvic bone resection and the large amount of foreign material implanted in the surgical wound [19-21]. It is reported that the use of vancomycin in the cement spacer gives better local control in infected reconstructions after resection for bone tumours [22]. Buchholz and Gartmann reported local levels of antibiotic 200-times higher than those achieved by systemic administration. Some authors suspected that local high concentrations of antibiotic released from antibiotic-impregnated cement is the most important factor in the prevention of occurrence of infection $[23,24]$. In our study, two patients had staphylococcus aureus infection; both of them underwent chemotherapy.

It is important in ilium resection to transfer the shear stress to compressional stress between the pedicle screwrod system and the sacrum; otherwise, shear stress could induce loosening and displacement. It has been shown that the ischium plays a role in the loading transfer both in standing and in sitting, so the prosthesis should be fixed on the remaining branch of the ischium; an additional ischial tubercle should be considered while the ischium is resected [25]. One patient in our study had pubic symphysis subluxation seven months after surgery (Fig. 4A), which might be due to this. We also considered the following reasons: walking too early; excessive weight; the USS pedicle screw-rod system radian not being firmly secured enough; or the sacroiliac joint, hip and pubic symphysis forming a lever, leading to pubic symphysis dislocation upon application of weight. A definitive reason would require larger sample verification.

It is advantageous to use the USS pedicle screw-rod system for reconstruction after type I + IV pelvic resection because it saves mobile lumbar segments [26]. The USS pedicle screw-rod construction augmented with autologous bone graft has the advantage of allowing flexibility of reconstruction of sacroiliac joint tumours. This is a simple reconstructive procedure without tedious preoperative customisation, lower infection rates and decreased concentration of stress by multi-point fixation of screws. The current study shows that reconstruction with the pedicle screw-rod after resection of sacroiliac joint tumours is a safe method that has the advantages of rapid rehabilitation and short hospital stays, lower complication rates and favourable functional results with most patients achieving independent ambulation and excellent cosmetics. This method is a good alternative to treat patients with sacroiliac joint tumours.

The characteristics of using the pedicle screw-rod system augmented with autologous bone graft to reconstruct sacroiliac joints after resection of sacroiliac joint tumours are as follows: (1) The pedicle screw-rod system can allow appropriate pressure on autologous bone, which can promote planting bone healing and pelvic ring stability, and belongs to the biological reconstruction. However, there are some problems, especially allograft nonunion, allograft not healing and rejection and infection risk. (2) The surgical indications of using the pedicle screw-rod system augmented with autologous bone graft to reconstruct a sacroiliac joint after resection of a sacroiliac joint tumour: I or I + IV areas of pelvic primary tumour; isolated metastasis tumour; reserving the top of the acetabulum of the pubis and sciatic after tumour excision; especially the survival period of patients, which is expected to be more than half a year. But this method is technology contraindicated to the isolated areas II or III of pelvic primary tumours because often it cannot guarantee the stability of the pedicle screw-rod system or complete cutting edge after resection of the tumour.

In conclusion, use of a pedicle screw-rod after resection of a sacroiliac joint tumour is an acceptable method of pelvic reconstruction because of its lower rate of complications and satisfactory functional outcome, as well as its feasibility of reconstruction for type IV pelvis tumour resection without elaborate preoperative customisation. It is a practical operation for reconstruction of the sacroiliac joint by the pedicle screw-rod system after resection of a sacroiliac joint tumour. It is characterised by its easy manipulation, few complications and stable fixation.

The authors declare no conflict of interest. 


\section{References}

1. Cottias P, Jeanrot C, Vinh TS. Complications and functional evalu ation of 17 saddle prostheses for resection of periacetabular tumors. J Surg Oncol 2001; 78: 90-100.

2. Gradinger R, Rechl H, Hipp E. Pelvic osteosarcoma. Resection, reconstruction, local control, and survival statistics. Clin Orthop Relat Res 1991; 270: 149-58.

3. Satcher Jr RL, O'Donnell RJ, Johnston JO. Reconstruction of the pelvis after resection of tumors about the acetabulum. Clin Orthop Relat Res 2003; 409: 209-17.

4. Langlais F, Lambotte JC, Thomazeau H. Long-term results of hemipelvis reconstruction with allografts. Clin Orthop Relat Res 2001; 388: 178-86.

5. Hugate R, Sim FH. Pelvic Reconstruction Techniques. Orthop Clin North Am 2006; 37: 85-97.

6. Mankin HJ, Hornicek FJ, Temple HT. Malignant tumors of the pelvis: an outcome study. Clin Orthop Relat Res 2004; 425: 212-7.

7. Satcher Jr RL, O'Donnell RJ, Johnston JO, et al. Reconstruction of the pelvis after resection of tumors about the acetabulum. Clin Orthop Relat Res 2003; 409: 209-17.

8. Müller PE, Dürr HR, Wegener B, et al. Internal hemipelvectomy and reconstruction with a megaprosthesis. Int Orthop 2002; 26: 76.

9. Enneking WF, Spanier SS, Goodman MA. Asystem for the surgical staging of musculoskeletal sarcoma. Clin Orthop Relat Res 1980 153: 106-120.

10. Enneking WF, Dunham W, Gebhardt MC, et al. system for the functional evaluation of reconstructive procedures after surgical treatment of tumors of the musculoskeletal system. Clin Orthop Relat Res 1993; 286: 241-246.

11. Müller PE, Dürr HR, Wegener B, et al. Internal hemipelvectomy and reconstruction with a megaprosthesis. Int Orthop 2002; 26: 76

12. Guo Z, Li J, Pei GX, Li XD, Wang Z. Pelvic reconstruction with a combined hemipelvic prostheses after resection of primary malignant tumor. Surg Oncol 2010; 19: 95-105.

13. Bell RS, Davis AM, Wunder JS, et al. Allograft reconstruction of the acetabulum after resection of stage-IIB sarcoma. Intermediate-term results. J Bone Joint Surg Am 1997; 79-A: 1663-74.

14. Enneking WF. Modification of the system for functional evaluation of surgical management of musculoskeletal tumors. In: Enneking WF (ed.). Limb salvage in musculoskeletal oncology. Bristol-Myers/Zimmer Orthopaedic Symposium. Churchill Livingstone, New York 1987; 626

15. Ozaki T, Hoffmann C, Hillmann A, Gosheger G, Lindner N, Winkelmann W. Implantation of hemipelvic prosthesis after resection of sarcoma. Clin Orthop Relat Res 2002; 396: 197-205.

16. Matsuo T, Sugita T, Sato K, et al. Clinical outcomes of 54 pelvic osteosarcomas registered by Japanese musculoskeletal oncology group. Oncology 2005; 68: 375

17. Müller PE, Dürr HR, Wegener B, Pellengahr C, Refior HJ, Jansson V. Internal hemipelvectomy and reconstruction with a megaprosthesis. Int Orthop 2002; 26: 76-79.

18. Delloye C, Banse X, Brichard B, Docquier PL, Cornu O. Pelvic reconstruction with a structural pelvic allograft after resection of a malignant bone tumor. J Bone Joint Surg Am 2007; 89: 579-87.

19. Aljassir F, Beadel GP, Turcotte RE, Griffin AM, Bell RS, Wunder JS, Isler $\mathrm{MH}$. Out come after pelvic sarcoma resection reconstructed with saddle prosthesis. Clin Orthop Relat Res 2005; 438: 36-41.

20. Hillmann A, Hoffmann C, Gosheger G, Rödl R, Winkelmann W, Ozaki T. Tumors of the pelvis: complications after reconstruction. Arch Orthop Trauma Surg 2003; 123: 340-4.

21. Enneking WF, Dunham WK. Resection and reconstruction for primary neoplasms involving the innominate bone. J Bone Joint Surg Am 1978; 60: 731-46.

22. Donati D, Biscaglia R. The use of antibiotic impregnated cement in infected reconstructions after resection for bone tumors. J Bone Joint Surg Br 1998; 80: 1045-50.

23. Buchholz HW, Gartmann HD. Infection prevention and surgical management of deep insidious infection intotal endoprosthesis. Chirurg 1972; 43: 446-53.
24. Wahlig H, Dingeldein E, Buchholz HW, et al. Pharmacokinetic study of gentamicinloaded cement intotal hip replacements. Comparative effects of varying dosage. J Bone Joint Surg Br 1974; 66: 175-9.

25. Dai KR, Yan MN, Zhu ZA, Sun YH. Computer-aided custom-made hemipelvic prosthesis used in extensive pelvic lesions. J Arthroplasty 2007; 22: 981-6.

26. Aydinli U, Akesen B, Alçinkaya U. Iliosacral fixation after type-1 hemipelvectomy: a novel technique. J Acta Orthop Belg 2012; 78: 393-7.

\section{Address for correspondence}

Xing-Hua Song PhD, MD

Orthopaedic Department

The First Affiliated Hospital of Xinjiang Medical School

New Medical Road

Urumqi 830054, PR China

tel. $+8609914366790,13199836661$

e-mail: songxinghua19@163.com

Submitted: 22.04.2013

Accepted: 12.11 .2013 